\title{
HUBUNGAN OBESITAS DENGAN TEKANAN DARAH DI RT 05 DESA KALISAPU KECAMATAN SLAWI KABUPATEN TEGAL TAHUN 2015
}

\author{
Seventina Nurul Hidayah \\ Program Studi D III Kebidanan Politeknik Harapan Bersama \\ Jl.Mataram no.09 Pesurungan Lor Kota Tegal
}

\begin{abstract}
Abstrak
Hipertensi merupakan masalah kesehatan yang sering di temukan di tengah masyarakat dan mengakibatkan angka kesakitan yang tinggi. Faktor yang memicu terjadinya hipertensi salah satunya adalah obesitas. Penelitian ini bertujuan untuk mengetahui hubungan antara obesitas dengan tekanan darah pada warga di RT.05 Desa Kudaile Kecamatan Slawi Kabupaten Tegal. Metode yang digunakan yaitu Analitik korelasional dengan populasi seluruh warga yang menderita obesitas di RT 05 Desa Kudaile Kecamatan Slawi Kabupaten Tegal sejumlah 40 responden dipilih sebagai sampel dengan menggunakan teknik purposive sampling. Kecamatan Slawi Kabupaten Tegal

Hasil penelitian menunjukkan bahwa nilai $\mathrm{P}$ pada hasil perhitungan dengan rumus Spearman Rho adalah 0,243 hal ini menunjukkan tidak terdapat hubungan antara obesitas dengan tekanan darah pada warga di RT.05 Desa Kalisapu Kecamatan Slawi Kabupaten Tegal. Dari penelitian ini diharapkan warga dapat mengendalikan berat badan dan tekanan darah dengan mengatur pola hidup sehat demi keselamatan bersama dari ancaman meluasnya penyakit-penyakit degeneratif seperti hipertensi.
\end{abstract}

\section{Kata kunci : Obesitas, Tekanan darah}

\section{Pendahuluan}

Obesitas adalah keadaan dimana seseorang memiliki berat badan yang lebih berat dibandingkan berat badan idealnya yang disebabkan karena ketidak seimbangan antara asupan dan keluaran energi (Arisman, 2004). Selain faktor keturunan dan faktor lingkungan, faktor asupan makanan yang berlebih atau obesitas ikut andil sebagai penyebab meningkatnya prevalensi tekanan darah tinggi atau hipertensi (Lili Marliani, 2007). Tekanan darah adalah tekanan yang dialami darah pada pembuluh arteri ketika darah dipompa oleh jantung ke seluruh tubuh (Poirier P.Giles TD,2005). Tekanan darah dapat berupa tekanan darah rendah atau hipotensi, normal maupun tekanan darah tinggi atau hipertensi.

Hipertensi mempunyai resiko yang besar untuk menyebabkan kematian pada manusia karena komplikasinya ke beberapa organ vital. Menurut Joint National Committee on Detection Evaluation and Treatment of High Blood Pressure (JNC) hipertensi adalah tekanan darah yang lebih tinggi dari 140/90 $\mathrm{mmHg}$ dan diklasifikasikan sesuai derajat keparahannya, mempunyai rentang dari tekanan darah normal tinggi sampai hipertensi maligna. Sedangkan hipotensi adalah suatu keadaan dimana tekanan darah seseorang turun dibawah angka normal, yaitu mencapai nilai lebih rendah dari 90/60 mmHg (Damon Runyan, 2008)

Berdasarkan hasil riset kesehatan dasar (Riskedas) di Propinsi Jawa Timur pada tahun 2008 terdapat $31,3 \%$ penderita hipertensi, tahun 2009 menjadi 34,6\% dan tahun 2010 meningkat menjadi 38,3\% pasien dari total jumlah penduduk. Berdasarkan data awal yang diperoleh dari Puskesmas Slawi penderita hipertensi pada tahun 2011 sejumlah 7995 pasien, tahun 2012 menunjukkan peningkatan yaitu 8265 pasien dan pada tahun 2013 meningkat lagi menjadi 8455 pasien. Dari 30 orang warga RT 05 Desa Kalisapu yang dilakukan pengukuran, 12 orang terdeteksi obesitas dan menderita hipertensi. 
Tekanan darah dapat dipengaruhi oleh beberapa faktor resiko antara lain: usia, riwayat keluarga, gaya hidup, jenis kelamin, kelebihan berat badan atau obesitas. Menurut Tjandra Yoga Aditama (Kementrian kesehatan), prevalensi obesitas pada penduduk umur 15 tahun ke atas sebanyak $19,1 \%$ dan akan semakin meningkat seiring dengan bertambahnya penderita obesitas orang Indonesia, keadaan tersebut tentu saja dapat mempengaruhi peningkatan prevalensi hipertensi. Untuk memantau status gizi orang dewasa, khususnya yang berkaitan dengan kekurangan dan kelebihan berat badan dapat menggunaka alat atau cara yang sederhana yaitu Indeks Massa Tubuh (IMT) atau Body Mass Index (BMI).

Obesitas yang muncul pada usia remaja cenderung berlanjut hingga ke dewasa, dan lansia. Sementara obesitas itu sendiri merupakan faktor risiko penyakit degeneratif seperti penyakit kardiovaskuler, diabetes melitus, artritis, beberapa jenis kanker, penyakit kantung empedu dan gangguan fungsi pernapasan (Arisman, 2004).

Mempertahankan berat badan dan tekanan darah dalam batas normal memungkinkan seseorang dapat mencapai usia harapan hidup yang lebih panjang (Mansjoer.A, 2001). Cara menghindari semakin meningkatnya angka penderita hipertensi, masyarakat harus mampu mengendalikan tekanan darah dan dapat menerapkan pola hidup sehat, seperti : mengurangi berat badan yang berlebihan, tidak merokok, tidak minum minuman yang mengandung alkohol, dan melakukan olahraga ringan secara teratur.

Dari uraian diatas menunjukkan prevalensi hipertensi atau kelainan tekanan darah dari tahun ke tahun semakin meningkat dan hal tersebut dapat dipicu oleh beberapa faktor resiko salah satu diantaranya adalah kelebihan berat badan atau obesitas, oleh sebab itu peneliti tertarik untuk melakukan penelitian tentang hubungan obesitas dengan tekanan darah.

\section{Metode Penelitian}

A. Tempat dan Waktu Penelitian

Penelitian ini dilakukan di Desa Kalisapu

Kecamatan Slawi Kabupaten Tegal yaitu RT 05

\section{B. Jenis Penelitian}

Jenis penelitian adalah deskriptif korelasi untuk mengetahui hubungan antara dua variabel pada suatu situasi atau sekelompok subjek. Penelitian ini menggunakan pendekatan Cross Sectional.

C. Populasi dan Sampel

Populasi penelitian ini adalah seluruh warga yang menderita obesitas di RT 05 Desa Kalisapu Kecamatan Slawi Kabupaten Tegal . Pada penelitian ini sampel adalah orang dewasa yang menderita obesitas di RT 05 Desa Kudaile dengan kriteria sampel bersedia untuk menjadi responden, berusia antara 18-60 tahun, (IMT) Indeks Massa Tubuh $>25$, tidak sedang menderita penyakit kronik dan tidak sedang mengkonsumsi obat antihipertensi.

D. Variabel Penelitian

Variabel independen dalam penelitian ini adalah obesitas. Variabel dependen dalam penelitian ini adalah hipertensi.

E. Instrumen Penelitian

Alat pengumpulan data pada penelitian ini berupa kuisioner yang dibuat sendiri oleh peneliti berdasarkan konsep teoritisnya, yang terdiri dari 15 pertanyaan multiple choice untuk mengetahui obesitas dan tekanan darah. Untuk mengetahui hubungan antara obesitas dengan nilai tekanan darah pada orang dewasa, maka digunakan uji Korelasi Spearman Rank (Rho).

Jika harga $t$ hitung lebih besar dari $t$ tabel maka $\mathrm{H}_{\mathrm{O}}$ ditolak atau jika menggunakan perangkat lunak computer $\mathrm{H}_{0}$ diterima bila angka signifikansi $>\alpha$ dan $\mathrm{H}_{1}$ diterima bila angka signifikansi $<\alpha$ dengan $(\alpha=0,05)$.

F. Analisis Data

1) Analisis univariat

Dengan menggunakan statistik deskriptif berupa proporsi distribusi frekuensi untuk mengetahui gambar mengenai variabel independent dan dependen.

\section{2) Analisis bivariat}

Analisa data bersifat bivariat untuk mengetahui dua variabel. Data yang terkumpul dianalisa dengan uji statistik 
korelasi dengan menggunakan uji chisquare untuk mengetahui hubungan variabel independen dengan variabel dependen.

Rumus uji chi-square:

$$
\text { a. } \quad X^{2}=\sum \frac{(F o-F h)^{2}}{F h}
$$

Keterangan :

3) $X^{2} \quad$ :chi-square

4) Fo : Frekuensi yang diobservasi

5) $\mathrm{Fh}$ : Frekuensi yang diharapkan

6) Kesimpulan : hipotesis nol (Ho) ditolak apabila nilai $\mathrm{X}^{2}$ hitung lebih besar dari $\mathrm{X}^{2}$ tabel atau nilai $\mathrm{p}$ lebih kecil dari alpha $(\alpha=0,05)$.

\section{Hasil Dan Pembahasan}

Dalam bab ini akan diuraikan tentang hasil penelitian dan pembahasan dengan judul Hubungan Obesitas dengan Tekanan Darah Pada Warga di RT.05 di Desa Kalisapu Kecamatan Slawi Kabupaten Tegal yang akan dibagi menjadi dua bagian yaitu data umum dan data khusus.

Data umum yang berisi karakteristik responden yang terdiri dari usia, jenis kelamin, tingkat pendidikan responden. Data khusus membahas Hubungan Obesitas dengan Tekanan Darah Pada Warga di RT.05 Desa Kalisapu Kecamatan Slawi Kabupaten Tegal

A. Gambaran Lokasi Penelitian

Penelitian ini dilakukan di wilayah kerja Desa Kalisapu Kecamatan Slawi Kabupaten Tegal RT.05 pada tanggal 16-31 Mei 2015, penelitian ini dilakukan pada warga sehingga pengukuran dapat dilakukan kepada satu orang atau lebih dalam satu keluarga yang sebelumnya telah bersedia menjadi responden.

B. Data Umum

1) Karakteristik Reponden Berdasar Usia Tabel 1 Tabel Distribusi Frekuensi Responden Berdasarkan Usia di RT.05 Desa Kalisapu Kecamatan Slawi Kabupaten Tegal, bulan Mei 2015

\begin{tabular}{cccc}
\hline No. & Usia & F & \% \\
\hline 1 & $18-30$ tahun & 9 & $30 \%$ \\
2 & $31-45$ tahun & 15 & $50 \%$ \\
3 & $46-60$ tahun & 6 & $20 \%$ \\
\hline & Jumlah & 30 & $100 \%$ \\
\hline
\end{tabular}

Sumber data: lembar observasi penelitian
Berdasarkan table 4.1 di atas menunjukkan bahwa usia warga sebagai responden usia 18-30 tahun sebanyak 9 responden (30\%), 31-45 tahun sebanyak 15 responden $(50 \%)$ dan 46-60 tahun sebanyak 6 responden $(20 \%)$

2) Karakteristik Responden Berdasarkan Jenis Kelamin

Table 2 Tabel Distribusi Frekuensi Responden Berdasarkan Jenis Kelamin di RT.05 Desa Kalisapu Kecamatan Slawi Kabupaten Tegal, bulan Mei 2015

\begin{tabular}{cccc}
\hline No. & Jenis & Frekuen & Prosentas \\
& Kelamin & si & e \\
1 & Laki-Laki & 12 & $40 \%$ \\
2 & Perempuan & 18 & $60 \%$ \\
& Jumlah & 30 & $100 \%$ \\
\hline
\end{tabular}

Sumber data: lembar observasi penelitian

Berdasarkan tabel 4.2 di atas menunjukkan bahwa yang berjenis kelamin Laki-laki sebanyak 12 responden (40\%), dan perempuan sebanyak 18 responden $(60 \%)$.

3) Karakteristik Responden Berdasarkan Tingkat Pendidikan

Table 3 Tabel Distribusi Frekuensi Responden Berdasarkan Tingkat Pendidikan di RT.05 Desa Kalisapu Kecamatan Slawi Kabupaten Tegal, bulan Mei 2015

\begin{tabular}{cccc}
\hline No. & Pendidikan & Frekuensi & Prosentase \\
\hline 1 & SD & 9 & $30 \%$ \\
2 & SMP & 10 & $33,3 \%$ \\
3 & SMA & 8 & $26,7 \%$ \\
4 & D3/SI & 3 & $10 \%$ \\
\hline & Jumlah & 30 & $100 \%$ \\
\hline
\end{tabular}

Sumber data: lembar observasi penelitian

Berdasarkan tabel 3 di atas menunjukkan bahwa pendidikan warga sebagai responden tingkat SD sebanyak 9 respoden (30\%), SMP sebanyak 10 responden $(33,3 \%)$, SMA sebanyak 8 responden $(26,7 \%)$ dan D3/S1 sebanyak 3 responden $(10 \%)$ 


\section{Data Khusus}

1) Obesitas

Tabel 4 Tabel Distribusi Frekuensi Tingkat Obesitas masyarakat di RT.05 Desa Kalisapu Kecamatan Slawi Kabupaten Tegal, bulan Mei 2015

\begin{tabular}{cccc}
\hline No. & $\begin{array}{c}\text { Tingkat } \\
\text { Obesitas }\end{array}$ & f & Prosentase \\
\hline 1 & Ringan & 21 & $70 \%$ \\
2 & Sedang & 7 & $23,3 \%$ \\
3 & Berat & 2 & $6,7 \%$ \\
\hline & Jumlah & 30 & $100 \%$ \\
\hline
\end{tabular}

Sumber data: lembar observasi penelitian

Berdasarkan tabel 4.4 di atas menunjukkan bahwa tingkat obesitas warga sebagai responden pada tingkat obesitas ringan sebanyak 21 responden $(70 \%)$, obesitas sedang sebanyak 7 responden $(23,3 \%)$ dan obesitas berat sebanyak 2 responden $(6,7 \%)$

\section{2) Tekanan Darah}

Tabel 5 Tabel Distribusi Frekuensi Tekanan Darah masyarakat di RT.05 Desa Kalisapu Kecamatan Slawi Kabupaten Tegal, bulan Mei 2015

\begin{tabular}{cccc}
\hline No. & $\begin{array}{c}\text { Tekanan } \\
\text { Darah }\end{array}$ & F & $\mathbf{\%}$ \\
\hline 1 & Hipotensi & 2 & $6,6 \%$ \\
2 & Normal & 17 & $56,6 \%$ \\
3 & Hipertensi & 11 & $36,7 \%$ \\
\hline & Jumlah & 30 & $100 \%$ \\
\hline
\end{tabular}

Sumber data: lembar observasi penelitian

Berdasarkan tabel 4.5 di atas menunjukkan bahwa tekanan darah warga sebagai responden pada tingkat hipotensi sebanyak 2 responden $(6,6 \%)$, normal sebanyak 17 responden $(56,6 \%)$ dan hipertensi sebanyak 11 responden $(36,7 \%)$

3) Hubungan Obesitas dengan Tekanan Darah

Tabel 6 Tabel Tabulasi Silang Hubungan Antara Obesitas dengan Tekanan Darah Pada Warga di RT.05 Desa Kalisapu Kecamatan Slawi Kabupaten Tegal, bulan Mei 2015

\begin{tabular}{|c|c|c|c|c|c|c|c|c|}
\hline \multirow{3}{*}{ IMT } & \multicolumn{8}{|c|}{ Tekanan Darah } \\
\hline & \multicolumn{2}{|c|}{ Hipotensi } & \multicolumn{2}{|c|}{ Normal } & \multicolumn{2}{|c|}{ Hipertensi } & \multicolumn{2}{|c|}{ Total } \\
\hline & $\sum$ & $\%$ & $\sum$ & $\%$ & $\Sigma$ & $\%$ & $\Sigma$ & $\%$ \\
\hline $\begin{array}{l}\text { Obesitas } \\
\text { tingkat } \\
\text { ringan }\end{array}$ & 1 & 3,3 & 14 & 46,7 & 7 & 23,3 & 22 & 73,3 \\
\hline $\begin{array}{l}\text { Obesitas } \\
\text { tingkat } \\
\text { sedang }\end{array}$ & 0 & 0 & 4 & 13,3 & 2 & 6,7 & 6 & 20,0 \\
\hline $\begin{array}{l}\text { Obesitas } \\
\text { tingkat } \\
\text { berat }\end{array}$ & 0 & 0 & 0 & 0 & 2 & 6,7 & 2 & 6,7 \\
\hline Total & 1 & 3,3 & 18 & 60,0 & 11 & 36,7 & 30 & 100 \\
\hline $\begin{array}{l}\text { Hasil uji } \\
\text { P }(0,243)\end{array}$ & ( & $\begin{array}{l}\text { ho } \\
\Rightarrow \mathrm{H}\end{array}$ & $\begin{array}{l}\text { apa } \\
\text { lite }\end{array}$ & $\begin{array}{l}\text { in ha } \\
\text { a }(1\end{array}$ & 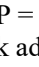 & $\begin{array}{l}3 \\
\text { bun }\end{array}$ & & \\
\hline
\end{tabular}

Tabel diatas menunjukkan bahwa klien yang menderita obesitas tingkat ringan 22 orang $(73,3 \%)$ dengan 1 orang $(3,3 \%)$ kategori hipotensi, 14 orang $(46,7 \%)$ normal, 7 orang $(23,3 \%)$ hipertensi. Klien dengan obesitas tingkat sedang 6 orang $(20 \%)$ dengan 4 orang $(13,3 \%)$ kategori normal, 2 orang $(6,7 \%)$ hipertensi. Klien dengan obesitas tingkat berat 2 orang $(6,7 \%)$ dan semua menderita hipertensi. Dari hasil uji Spearman Rho didapatkan hasil P 0,243 dengan demikian maka $\mathrm{H}_{0}$ diterima dan $\mathrm{H} 1$ ditolak. Hal ini mempunyai arti tidak ada hubungan antara obesitas dengan tekanan darah.

\section{Pembahasan}

A. Obesitas

Dari hasil penelitian didapatkan bahwa dari 30 responden yang diobservasi, 21 orang $(70 \%)$ mengalami obesitas tingkat ringan, 7 orang $(23,3 \%)$ obesitas tingkat sedang dan 2 orang $(6,7 \%)$ obesitas tingkat berat. Hal ini menunjukkan bahwa sebagian besar responden mengalami obesitas tingkat ringan

Menurut Arisman (2004) Obesitas adalah keadaan dimana seseorang memiliki berat badan yang lebih berat dibandingkan berat badan idealnya disebabkan karena ketidak seimbangan antara asupan dan keluaran energi. Banyak faktor resiko yang dapat mempengaruhi terjadinya obesitas antara lain adalah faktor genetik, psikososial, kesehatan, perkembangan, 
obat-obatan tertentu, aktivitas fisik dan faktor lingkungan. Meningkatnya taraf hidup masyarakat dan tuntutan hidup serba cepat berpengaruh terhadap pola makan, saat ini masyarakat lebih memilih makanan siap saji yang umumya rendah serat, tinggi lemak, tinggi gula, dan mengandung banyak garam. Obesitas secara langsung berbahaya bagi kesehatan seseorang karena dapat meningkatkan resiko terjadinya beberapa penyakit seperti diabetes melitus, hipertensi, artritis, beberapa jenis kanker, penyakit kantung empedu dan gangguan fungsi pernapasan (Arisman, 2004).

Mempertahankan berat badan dan tekanan darah dalam batas normal memungkinkan seseorang dapat mencapai usia harapan hidup yang lebih panjang (Mansjoer.A, 2001). Dari hasil penelitian menunjukkan bahwa responden cenderung obesitas tingkat ringan sehingga kemungkinan akan mengalami penyakit kardiovaskuler relative kecil

B. Tekanan darah

Berdasarkan hasil penelitian didapatkan bahwa kriteria tekanan darah responden sebagian besar dalam batas normal dengan jumlah 17 orang $(56,6 \%)$, hipertensi sebanyak 11 orang $(36,7 \%)$ dan hipotensi sebanyak 2 orang $(6,6 \%)$.

Tekanan darah adalah tekanan yang digunakan untuk mengedarkan darah dalam pembuluh darah dalam tubuh. Jantung yang berperan sebagai pompa otot mensuplai tekanan tersebut untuk menggerakan darah dan juga mengedarkan darah diseluruh tubuh. Pembuluh darah (dalam hal ini arteri) memiliki dinding-dinding yang elastis dan menyediakan resistensi yang sama terhadap aliran darah. Oleh karena itu, ada tekanan dalam sistem peredaran darah, bahkan detak jantung (Gardner, 2007).

Dari tabel 1 terdapat 30 responden dengan karakteristik responden berdasarkan usia pada warga di RT.05 Desa Kalisapu Kecamatan Slawi Kabupaten Tegal yang terbanyak adalah usia antara 31-45 tahun yaitu sebanyak
14 orang $(46,7 \%)$, usia $18-30$ tahun sebanyak 10 orang $(33,3 \%)$, usia $46-60$ tahun sebanyak 6 orang $(20,0 \%)$. Menurut Gunawan (2001) semakin bertambahnya umur maka tekanan darah juga meningkat. Alasan tersebut diperkuat oleh Anindya (2009) dimana insidensi hipertensi meningkat seiring dengan pertambahan usia, hal itu merupakan pengaruh degenerasi yang terjadi pada orang yang bertambah usianya.

Bila ditinjau perbandingan antara perempuan dan laki - laki, ternyata perempuan lebih banyak menderita hipertensi (Fransisca, 2010). Ini dapat dibuktikan dari hasil penelitian, dari keseluruhan responden yang menderita hipertensi sebanyak 11 orang, penderita hipertensi perempuan sebanyak 6 orang $(54,5 \%)$ dan laki-laki sebanyak 5 orang (45,5\%). Menurut Anindya (2009), lakilaki mempunyai resiko lebih tinggi untuk menderita hipertensi lebih awal. Lakilaki juga mempunyai resiko yang lebih besar terhadap morbiditas dan mortalitas kardiovaskuler. Diharapkan semua warga dapat melakukan pencegahan dini dengan memeriksakan diri ke fasilitas kesehatan terdekat dan rutin mengkonsumsi obat yang diberikan oleh dokter pada penderita kelainan tekanan darah atau hipertensi.

C. Hubungan obesitas dengan tekanan darah

Hasil perhitungan dengan uji statistik menggunakan rumus Spearman Rho didapatkan nilai $\mathrm{P} \quad 0,243$ hal ini menunjukkan tidak terdapat hubungan antara obesitas dengan tekanan darah pada warga RT.05 Desa Kalisapu Kecamatan Slawi Kabupaten Tegal

Faktor yang dapat dikendalikan oleh manusia agar terhindar dari penyakit tekanan darah tinggi yaitu obesitas atau kegemukan, asupan garam, stress, rokok, kafein, alkohol dan olahraga Menurut ( Yien, 2008).

Ada beberapa kaitan antara obesitas dengan tekanan darah yaitu pada kondisi obesitas dapat terjadi resistensi insulin yang dapat berpotensi menghilangkan kerja insulin dalam mempertahankan 
tekanan darah yang normal serta dapat terjadi peningkatan jumlah Asam Lemak Bebas (ALB) yang akan mempersempit pembuluh darah sehingga tekanan darah akan meningkat, namun hal tersebut dapat dicegah melalui pengontrolan pola atau gaya hidup, seperti : mengkonsumsi makanan yang mengandung kalium, magnesium dan kalsium, mengurangi minum minuman atau makanan beralkohol, berolahraga secara teratur, makan sayur dan buah yang berserat tinggi, berhenti merokok, menjaga agar kadar kolesterol dan gula darah tetap normal, menjalankan terapi anti stres agar mengurangi stres dan mampu mengendalikan emosi, makukan konsultasi dengan ahli gizi secara rutin untuk mengatur pola makan yang sehat

Usaha hidup sehat dan mengenal cara - cara hidup sehat dari segala aspek kehidupan dan lingkungan akan memperkecil resiko serangan hipertensi (Dalimartha, 2008). Dari hasil penelitian ini terlihat bahwa pada warga dengan status obesitas tingkat ringan mayoritas memiliki tekanan darah normal sedangkan pada warga dengan status obesitas tingkat berat cenderung mengalami kelainan tekanan darah atau hipertensi, diharapkan warga dapat mengontrol diri dan lingkungannya demi keselamatan bersama dari ancaman meluasnya penyakit - penyakit degeneratif seperti hipertensi.

\section{Penutup}

Berdasarkan hasil penelitian mengenai hubungan obesitas dengan tekanan darah pada warga RT.05 Desa Kalisapu Kecamatan Slawi Kabupaten Tegal pada bulan Mei-Juni tahun 2015 dapat disimpulkan bahwa :

1. Sebagian besar $(70 \%)$ status obesitas pada warga RT.05 Desa Kalisapu Kecamatan Slawi Kabupaten Tegal adalah obesitas tingkat ringan.

2. Status tekanan darah pada warga RT.05 Desa Kalisapu Kecamatan Slawi Kabupaten Tegal sebagian besar $(60,0 \%)$ dalam kategori normal.

3. Nilai P pada hasil perhitungan dengan rumus Spearman Rho adalah 0,243 hal ini menunjukkan tidak terdapat hubungan antara obesitas dengan tekanan darah pada warga RT.05 Desa Kalisapu Kecamatan Slawi Kabupaten Tegal

\section{Daftar Pustaka}

[1] Arisman. (2004). Gizi dalam Daur Kehidupan. EGC. Jakarta

[2] Hidayat, A. Azis Alimul. (2007). Metode Penelitian Keperawatan Dan Teknik Ananlisis Data. Jakarta : Salemba Medika

[3] Lili Marliani. (2007). Tekanan Darah Tinggi. Jakarta : Balai Penerbit FKUI.

[4] Mansjoer, A. (2001). Kapita Selekta Kedokteran. Edisi 3 Jilid 1. Jakarta : Media Aesculapius.

[5] Damon Runyan. (2008). Mengenal, Mencegah, Mengatasi Silent Killer Hipertensi. Jawa Tengah-Indonesia : Penerbit Pustaka Widyamara.

[6] Poirier P.Giles TD.2005.Klasifikasi Hipertensi beserta Komplikasinya. Jakarta: Dian Rakya

[7] Nursalam. (2008) Konsep dan Penerapan Metodologi Penelitian Ilmu Keperawatan : Pedoman Sripsi, Tesis dan Instrumen Penelitian Keperawatan. Jakarta : Salemba Medika 